\title{
Is the SMART approach better than other treatment approaches for prevention of asthma exacerbations? A meta-analysis
}

\author{
R. Agarwal, A. Khan, A.N. Aggarwal, D. Gupta
}

ABSTRACT: Is the SMART approach better than other treatment approaches for prevention of asthma exacerbations? A meta-analysis. R. Agarwal, A. Khan, A.N. Aggarwal, D. Gupta.

Background and Aims. The combination of inhaled corticosteroids (ICS) and long-acting $\beta_{2}$ agonists (LABA) has been used as a single inhaler both for maintenance and reliever therapy in asthma, the SMART approach. The administration of additional CS with each reliever inhalation in response to symptoms is expected to provide better control of airway inflammation. The aim of this meta-analysis was to evaluate the efficacy and safety of the SMART approach versus other approaches in the management of asthma in preventing asthma exacerbations.

Methods. We searched the MEDLINE and EMBASE databases for studies that have reported exacerbations in the SMART group versus the control group. We calculated the odds ratio (OR) and $95 \%$ confidence intervals (CI) to assess the exacerbations in the two groups and pooled the results using a random-effects model.

Results. Our search yielded eight studies. The use of SMART approach compared to fixed-dose ICS-LABA combination significantly decreased the odds of a severe exacerbation (OR 0.65; 95\% CI, 0.53-0.80) and severe exacerbation requiring hospitalization/ER treatment (OR 0.69; 95\% CI, 058$0.83)$. The use of SMART approach compared to fixed-dose ICS also significantly decreased the odds of a severe exacerbation (OR 0.52; 95\% CI, 0.45-0.61) and severe exacerbation requiring medical intervention (OR 0.52; 95\% CI, 0.42-0.65). The occurrence of adverse events was similar in the two groups. There was some evidence of statistical heterogeneity.

Conclusions. The SMART approach using formoterol-budesonide is superior in preventing exacerbations when compared to traditional therapy with fixed dose ICS or ICS-LABA combination without any increase in adverse events.

Monaldi Arch Chest Dis 2009; 71: 4, 161-169.

Keywords: Bronchial asthma, Single inhaler, SMART approach, Inhaled corticosteroids, Long-acting beta agonists.

Department of Pulmonary Medicine, Postgraduate Institute of Medical Education and Research, Sector-12, Chandigarh 160012, India.

Correspondence: Dr. Ritesh Agarwal, Assistant Professor, Department of Pulmonary Medicine, Postgraduate Institute of Medical Education and Research, Sector-12,Chandigarh 160012,India; e-mail: riteshpgi@gmail.com

The authors have no conflicts to disclose.

\section{Introduction}

Inhaled corticosteroids (ICS) remain the cornerstone for the control for asthma [1,2]. However, many individuals continue to experience persistent symptoms despite treatment with inhaled corticosteroids [3]. In these poorly controlled asthmatics, addition of long acting $\beta_{2}$-agonists (LABA) achieves better control of asthma in terms of reduced symptoms and exacerbations, and improved lung function than increasing the dose of ICS $[3,4]$. Despite the combination of ICS-LABA, optimal asthma control is still not achieved and patients require reliever medications and continue to experience exacerbations [3-5]. This lack of optimal control may be attributed to periodic fluctuation in asthma symptoms and airway inflammation, which is difficult to control with as-needed reliever therapy (with $\beta_{2}$-agonists) alone that only provides rapid bronchodilation and symptom relief but fails to check the underlying airway inflammation.
During exacerbations, it has been demonstrated that the acme of the exacerbation is preceded by warning signs in the form of worsening symptoms for several days with patients responding with frequent use of reliever medications alone $[6,7]$. This reflects a window of missed opportunity during which patients could intervene early by increasing their asthma medications especially ICS. Recently, studies using a novel approach i.e. use of a single inhaler (of formoterol-budesonide) for both maintenance and reliever therapy (SMART) have been conducted. This strategy provides additional antiinflammatory therapy (because of budesonide) and rapid symptom relief (due to formoterol) during symptomatic periods. The SMART approach could logically enable patients to rapidly adjust their anti-inflammatory therapy during the warning phase of the exacerbation while simultaneously obtaining effective and rapid relief from symptoms.

Several recent reviews have suggested potential benefits of the SMART approach [8-10]. This 
study is designed to evaluate the effectiveness of the SMART approach (formoterol-budesonide combination as both maintenance and reliever therapy) in comparison to other approaches (fixed dose ICS or ICS/LABA combination with different reliever medication) for prevention of asthma exacerbations using a systematic review methodology. We chose severe asthma exacerbations as the outcome variable as these are not only one of the most sensitive clinical measures of control but are also precisely quantified [3].

\section{Material and methods}

\section{Search strategy and selection criteria}

To identify the studies for inclusion in this review, all the authors independently searched the computer database - MEDLINE and EMBASE for relevant studies published from 1988 to 2008 using free text terms: single inhaler for asthma, SMART approach for asthma, inhaled corticosteroids for asthma limiting the search to English literature, clinical trials and randomized controlled trials. Bibliographies of all selected articles and review articles that included information on the role of single inhaler therapy for maintenance and control of asthma were reviewed. In addition, we reviewed our personal files.

\section{Data abstraction}

The abstracts of the studies were independently reviewed by two authors (RA and AK), without blinding to study the details. Any disagreement was resolved by discussion between the authors. We included studies that had used the single inhaler approach using formoterol-budesonide combination both as maintenance and reliever therapy for asthma versus a control group. The control group could consist of asthma patients treated with either fixed dose ICS or ICS-LABA combination as their maintenance medication with a rapid action beta- 2 agonist (salbutamol, terbutaline or formoterol) as their as-needed reliever medicine. Data were recorded on a standard data extraction form. The following items were extracted: (a) publication details (title; author[s]); (b) prospective or retrospective nature of the study; (c) dosages and devices of ICS and ICS-LABA used in the various studies; (d) the age and the forced expiratory volume in the first second of the study participants; (e) the inclusion criteria, the definitions of exacerbations and compliance with study medications; and, (f) the occurrence of exacerbations (severe and requiring medical intervention) and the frequency of adverse effects (total and serious) in the SMART approach versus the control group.

The methodological quality of each trial was evaluated using the 5 -point scale $(0=$ worst and 5 = best) as described by Jadad et al [11]. This instrument assesses the adequacy of randomization, blinding, and the handling of withdrawals and dropouts and a score of one point for each 'yes' or zero points for each 'no'. One additional point is given if the method to generate the sequence of randomization was described and it was appropriate (table of random numbers, computer generated, etc.) or the method of double blinding was described and it was appropriate (identical placebo, active placebo, dummy, etc.). On the other hand one point is deducted if the method to generate the sequence of randomization was described and it was inappropriate (patients were allocated alternately, or according to date of birth, hospital number, etc.) or the study was described as double blind but the method of blinding was inappropriate (e.g., comparison of tablet vs. injection with no double dummy). The studies are said to be of low quality if the Jadad score is $\leq 2$ and high quality if score $\geq 3[11,12]$.

\section{Determination of the pooled treatment effect}

The statistical package StatsDirect (StatsDirect version 2.7.2 for MS-Windows, England, StatsDirect Ltd, 2005. http://www.statsdirect.com) and Review Manager (RevMan [Computer program], Version 5.0, Copenhagen, The Nordic Cochrane Centre, The Cochrane Collaboration, 2008) were used to perform the statistical analysis. We calculated the odds ratio (OR) and 95\% confidence intervals (CI) to assess the occurrence of exacerbations and the adverse effects in the SMART versus the control group. The results from individual studies were pooled using the random effects model of DerSimonian and Laird [13]. We also calculated the number needed to treat $(\mathrm{NNT}=1 /$ risk difference) with $95 \%$ CI to estimate the number of patients that need to be treated with SMART approach to prevent an exacerbation.

\section{Assessment of Heterogeneity}

The impact of heterogeneity on the pooled estimates of the individual outcomes of the metaanalysis was assessed the $\mathrm{I}^{2}$ test and the Cochran Q statistic. The $\mathrm{I}^{2}$ test measures the extent of inconsistency among the results of the studies, which are interpreted as the approximate proportion of total variation in study estimates that is due to heterogeneity rather than sampling error. An $\mathrm{I}^{2}$ value more than 50 percent indicates significant heterogeneity [14]. The Cochran test calculates the weighted sum of squared differences between individual study effects and the pooled effect across studies, with the weights being those used in the pooling method. The ( $p$ value) level at which heterogeneity should be diagnosed is unclear, given that the Q statistic has low power, and Fleiss et al has recommended a value of at least 0.1 [15].

An Institutional review board clearance was not required for this study as this was a metaanalysis of published studies.

\section{Results}

Our initial data search yielded a total of $1975 \mathrm{ci}-$ tations (figure 1). We excluded 1967 articles as they did not meet our inclusion criteria. Eight studies 


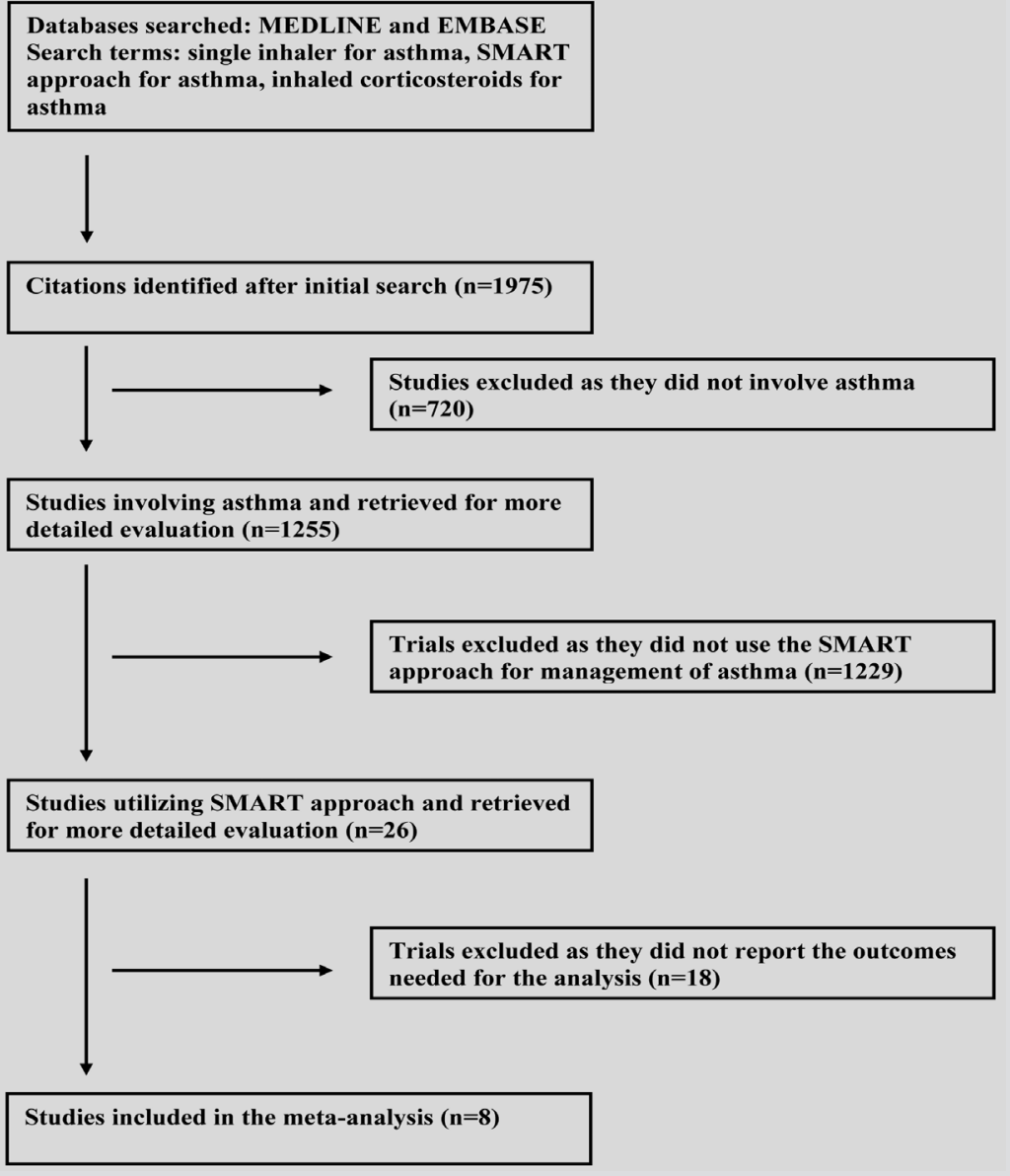

Fig. 1 - Trial selection process for the systematic review. were identified that have used the SMART approach for the management of asthma (tables 1-3) [16-23]. Of these, six studies have compared the SMART approach with fixed dose ICSLABA combination [17-19, 2123], and three studies have compared the SMART approach with fixed dose ICS treatment $[16,17,20]$. All the eight studies were prospective, randomized controlled trials, and all but two studies $[18,23]$ were blinded. The Jadad score was 3 for most of the studies indicating high quality of the individual studies (table 4). Majority of the studies included adults except the study by O'Byrne which also included children [17]. The mean $\mathrm{FEV}_{1}$ of the study participants and the dose of ICS used prior to entering the study are shown in table 1. The doses of ICS and ICSLABA used in the SMART and the control group are shown in table 2, and the inclusion criteria and the criteria used for definition of exacerbations in the various studies is listed in table 3 . The self-reported compliance with study medications was fairly high in all the trials (table 5).

Table 1. - Baseline characteristics, dose and device used by the participants in the various studies

\begin{tabular}{|c|c|c|c|c|c|c|}
\hline \multirow{2}{*}{$\begin{array}{l}\text { Author } \\
\text { (Year) }\end{array}$} & \multicolumn{2}{|c|}{ Mean age (range), years } & \multicolumn{2}{|c|}{ Mean $\mathrm{FEV}_{1}$ (range), \% } & \multicolumn{2}{|c|}{ Mean ICS dose (range), $\mu \mathrm{g}$} \\
\hline & SMART & Control & SMART & Control & SMART & Control \\
\hline $\begin{array}{l}\text { Scicchitano } \\
\text { (2004) [16] }\end{array}$ & $43(12-79)$ & $43(11-80)$ & $70(46-102)$ & $70(37-95)$ & $744(250-2000)$ & $748(400-2000)$ \\
\hline $\begin{array}{l}\text { O'Byrne } \\
\text { (2005) [17] }\end{array}$ & $35(4-77)$ & $\begin{array}{c}\text { ICS-36 (4-79); } \\
\text { ICS/LABA-36 (4-79) }\end{array}$ & $73(43-108)$ & $\begin{array}{c}\text { ICS-73 (49-100); } \\
\text { ICS/LABA-73 (46-108) }\end{array}$ & $619(200-1200)$ & $\begin{array}{l}\text { ICS-620 (100-1000); } \\
\text { ICS/LABA-598 (200-1000) }\end{array}$ \\
\hline $\begin{array}{l}\text { Vogelmeier } \\
(2005)[18]\end{array}$ & $45(12-80)$ & $45(12-84)$ & $73(39-115)$ & $73(28-100)$ & $888(50-2000)$ & $881(400-3000)$ \\
\hline $\begin{array}{l}\text { Rabe } \\
\text { (2006) [19] }\end{array}$ & $42(12-89)$ & $43(12-79)$ & $72(30-110)$ & $70(46-102)$ & $757(160-1600)$ & $754(250-1600)$ \\
\hline $\begin{array}{l}\text { Rabe } \\
\text { (2006) [20] }\end{array}$ & $38(12-79)$ & $38(11-78)$ & $75(51-123)$ & $75(52-109)$ & $353(200-500)$ & $343(200-500)$ \\
\hline $\begin{array}{l}\text { Bousquet } \\
\text { (2007) [21] }\end{array}$ & $40(12-80)$ & $39(12-80)$ & $70.2(45-114)$ & $71.0(45-222)$ & $705(250-1600)$ & $720(200-2000)$ \\
\hline $\begin{array}{l}\text { Kuna } \\
\text { (2007) [22] }\end{array}$ & $38 \pm 17(\mathrm{SD})$ & $\begin{array}{c}\text { ICS-38 } \pm 17 \text { (SD); } \\
\text { ICS-LABA-38 } \pm 17 \text { (SD) }\end{array}$ & $72 \pm 14$ (SD) & $\begin{array}{c}\text { ICS-73 } \pm 14 \text { (SD); } \\
\text { ICS-LABA-73 } \pm 14 \text { (SD) }\end{array}$ & 740 & 747 \\
\hline $\begin{array}{l}\text { Sears } \\
\text { (2008) [23] }\end{array}$ & $42.1(12-92)$ & $43.1(12-94)$ & $94.8(22-197)$ & $94.1(26-186)$ & $566(250-1600)$ & $572(160-2400)$ \\
\hline
\end{tabular}

$\mu$ : micrograms; BD: twice a day; bud: budesonide; DPI: dry powder inhaler; $\mathrm{FEV}_{1}$ : forced expiratory volume in the first second; ICS: inhaled corticosteroid; LABA: long acting $\beta_{2}$ agonists; SMART: single inhaler for maintenance and reliever therapy. 
Table 2. - Dose and device used for therapy in various studies

\begin{tabular}{|c|c|c|c|c|}
\hline \multirow{2}{*}{$\begin{array}{l}\text { Author } \\
\text { (Year) }\end{array}$} & \multicolumn{2}{|r|}{ Dose } & \multicolumn{2}{|c|}{ Device } \\
\hline & SMART & Control & SMART & Control \\
\hline $\begin{array}{l}\text { Scicchitano } \\
\text { (2004) [16] }\end{array}$ & $160 / 4.5 \mu \mathrm{g} 2 \mathrm{OD}+\mathrm{SOS}$ & Bud $160 \mu g$ BD + T 0.4 mg SOS & Turbuhaler & Turbuhaler \\
\hline $\begin{array}{l}\text { O’Byrne } \\
\text { (2005) [17] }\end{array}$ & $80 / 4.5 \mu \mathrm{g} 1 \mathrm{BD}+\mathrm{SOS}$ & $\begin{array}{l}\text { Bud } 320 \mu \mathrm{g} 1 \mathrm{BD}+\mathrm{T} 0.4 \mathrm{mg} \text { SOS; } \\
\text { bud/form } 80 / 4.5 \mu \mathrm{g} \mathrm{BD}+\text { T } 0.4 \mathrm{mg} \text { SOS }\end{array}$ & Turbuhaler & Turbuhaler \\
\hline $\begin{array}{l}\text { Vogelmeier } \\
(2005)[18]\end{array}$ & $160 / 4.5 \mu \mathrm{g} 2 \mathrm{BD}+\mathrm{SOS}$ & Salm/Flut 50/250 $\mu \mathrm{g} 2 \mathrm{BD}+$ Salb SOS & Turbuhaler & $\begin{array}{l}\text { Diskus \& Reliever } \\
\text { DPI or pMDI }\end{array}$ \\
\hline $\begin{array}{l}\text { Rabe } \\
(2006)[19]\end{array}$ & $160 / 4.5 \mu \mathrm{g} 1 \mathrm{BD}+\mathrm{SOS}$ & $\begin{array}{l}\text { Bud/form } 160 / 4.5 \mu \mathrm{g} 1 \mathrm{BD}+\mathrm{T} 0.4 \mathrm{mg} \text { SOS; } \\
\text { bud/form } 160 / 4.5 \mu \mathrm{g} 1 \mathrm{BD}+\text { form } 4.5 \mu \mathrm{g} \text { SOS }\end{array}$ & Turbuhaler & Turbuhaler \\
\hline $\begin{array}{l}\text { Rabe } \\
(2006)[20]\end{array}$ & $80 / 4.5 \mu g 2 \mathrm{OD}+\mathrm{SOS}$ & Bud 1602 BD + T 0.4 mg SOS & DPI & DPI \\
\hline $\begin{array}{l}\text { Bousquet } \\
(2007)[21]\end{array}$ & $160 / 4.5 \mu \mathrm{g} 2 \mathrm{BD}+\mathrm{SOS}$ & Salm/Flut 50/500 $\mu \mathrm{g} 1 \mathrm{BD}+\mathrm{T} 0.4$ mg SOS & Turbuhaler & $\begin{array}{l}\text { Diskus \& Reliever } \\
\text { with turbuhaler }\end{array}$ \\
\hline $\begin{array}{l}\text { Kuna } \\
(2007)[22]\end{array}$ & $160 / 4.5 \mu \mathrm{g} 1 \mathrm{OD}+\mathrm{SOS}$ & $\begin{array}{l}\text { Salm/Flut } 25 / 125 \mu \mathrm{g} 2 \text { BD + T } 0.4 \mathrm{mg} \text { SOS; } \\
\text { bud/form } 320 / 9 \mu \mathrm{g} 1 \mathrm{BD}+\mathrm{T} 0.4 \mathrm{mg} \text { SOS }\end{array}$ & Turbuhaler & $\begin{array}{l}\text { pMDI \& Reliever } \\
\text { with turbuhaler }\end{array}$ \\
\hline $\begin{array}{l}\text { Sears } \\
(2008)[23]\end{array}$ & $160 / 4.5 \mu \mathrm{g} 1 \mathrm{OD}+\mathrm{SOS}$ & Clinical best practice & Turbuhaler & Clinical best practice \\
\hline
\end{tabular}

$\mu \mathrm{g}$ : micrograms; DPI: dry powder inhaler; flut: fluticasone; form: formoterol; OD: once a day; pMDI: pressurized metered dose inhaler; salb: salbutamol; salm: salmeterol; SD: standard deviation; SOS: as-needed; T: terbutaline.

\section{SMART approach versus fixed-dose ICS-LABA combination}

The use of SMART approach compared to fixed-dose ICS-LABA combination significantly decreased the odds of occurrence of a severe exacerbation (six studies; 14,536 patients) with an OR of 0.65 (95\% CI, 0.53-0.8). It was also associated with decreased odds of developing severe exacerbation requiring hospitalization and/or ER treatment (five studies; 12,702 patients) with an OR of 0.69 (95\% CI, 0.58-0.83) (figure 2). The NNT of decreasing a severe exacerbation and severe exacerbation requiring ER/hospitalization was 18 (95\% CI, 15-22) and 53 (95\% CI, 39-85). There was evidence of statistical heterogeneity in the outcome of severe exacerbation as indicated by an $\mathrm{I}^{2}$ value of 77 percent and Cochran statistic of 21.34 with $\mathrm{p}$ value less than 0.01 (figure 2). There was clinical heterogeneity as indicated by the use of different drugs and doses of controller and reliever medications (table 2). The occurrence of adverse events including serious adverse events was not significantly different between the two groups (figure 3 ). The results were not significantly different even when the two unblinded studies $[18,23]$ were excluded from the analysis (OR 0.58 [95\% CI, 0.46-0.73] for severe exacerbation; OR 0.7 [95\% CI, 0.57-0.86] for severe exacerbation requiring $\mathrm{ER} /$ hospitalization).

\section{SMART approach versus fixed-dose ICS}

The use of SMART approach compared to fixed-dose ICS also significantly decreased the odds of occurrence of a severe exacerbation (three studies; 4437 patients) with an OR of 0.52 (95\% $\mathrm{CI}, 0.45-0.61)$. It was also associated with decreased odds of developing severe exacerbation requiring medical intervention (two studies; 3,724 patients) with an OR of 0.52 (95\% CI, 0.42-0.65) (figure 4). The NNT of decreasing a severe exacerbation and severe exacerbation requiring medical intervention was 10 (95\% CI, 8-13) and 12 (95\% CI, 9-16). There was no statistical heterogeneity in the any of the outcomes as indicated by an $\mathrm{I}^{2}$ value of less than 50 percent and Cochran Q statistic more than 0.01 (figure 4). The occurrence of adverse events including serious adverse events was not significantly different between the two groups (figure 5).

\section{Discussion}

The results of this study suggest that the SMART approach is better than conventional approaches in reducing exacerbations, both severe and those requiring medical intervention. In fact, the benefit is tremendous with a NNT of 18 and 10 (fixed dose ICS-LABA and fixed dose ICS respectively) meaning that one severe exacerbation can be prevented for every 10 patients treated with the SMART approach compared to ICS and 18 when compared to ICS-LABA. Further, this treatment approach was safe with no increase in adverse reactions when compared to the traditional approaches in the management of asthma. In fact, the benefit is even larger if one compares the absolute de- 
Table 3. - The definitions for inclusion criteria and exacerbations used by the different studies

\begin{tabular}{|c|c|c|}
\hline Author (Year) & Inclusion criteria & Exacerbation definition \\
\hline $\begin{array}{l}\text { Scicchitano } \\
(2004)[16]\end{array}$ & $\begin{array}{l}\text { Asthma (ATS) - } 6 \text { months; } \geq 1 \text { exacerbation in } 1 \text { year; } \\
\text { ICS } 400-1600 \mu \mathrm{g} / \mathrm{d} ; \mathrm{FEV}_{1} 50-90 \% \text { with } \geq 12 \% \text { and } 200 \mathrm{ml} \\
\text { increase after BDR }\end{array}$ & $\begin{array}{l}\text { SEVERE - hospitalization/ER therapy; } \\
\text { need for systemic steroids; PEFm fall } \leq 70 \% \\
\text { from baseline for } 2 \text { days }\end{array}$ \\
\hline $\begin{array}{l}\text { O’Byrne } \\
(2005)[17]\end{array}$ & $\begin{array}{l}4-80 \text { years with asthma treated with } 400-1000 \\
\mu \mathrm{g} / \mathrm{d} \text { ICS or } 200-500 \mu \mathrm{g} / \mathrm{d} \text { ICS-LABA; } \geq 1 \text { exacerbation } \\
\text { in } 1 \text { year; } \mathrm{FEV}_{1} 60-100 \% \text { with } \geq 12 \% \text { BDR }\end{array}$ & $\begin{array}{l}\text { SEVERE - hospitalization/ER therapy; } \\
\text { need for systemic steroids or } \uparrow \text { in ICS use; } \\
\text { PEFm fall } \leq 70 \% \text { from baseline }\end{array}$ \\
\hline $\begin{array}{l}\text { Vogelmeier } \\
(2005)[18]\end{array}$ & $\begin{array}{l}\geq 12 \text { years with asthma (ATS) - } 6 \text { months; } 1 \text { severe } \\
\text { exacerbation in } 2-12 \text { wks before study; budesonide } \\
>500 \mu \mathrm{g} / \mathrm{d} \text { or fluticasone }>1000 \mu \mathrm{g} / \mathrm{d} ; \mathrm{FEV}_{1} 40-90 \%\end{array}$ & $\begin{array}{l}\text { SEVERE - hospitalization/ER therapy; } \\
\text { need for systemic steroids for } 3 \text { days; } \\
\text { unscheduled hospital visit needing } \\
\text { treatment change }\end{array}$ \\
\hline $\begin{array}{l}\text { Rabe } \\
(2006)[19]\end{array}$ & $\begin{array}{l}>12 \text { yrs with asthma }>6 \text { months; } \geq 1 \text { exacerbation in } 1 \text { year; } \\
\text { ICS }>3 \text { months; } \mathrm{FEV}_{1} 50-100 \% \text { with } \geq 12 \% \text { BDR }\end{array}$ & $\begin{array}{l}\text { SEVERE - hospitalization/ER therapy; } \\
\text { need for systemic steroids }\end{array}$ \\
\hline $\begin{array}{l}\text { Rabe } \\
(2006)[20]\end{array}$ & $\begin{array}{l}\text { Asthma }>6 \text { months; } \mathrm{FEV}_{1} 60-100 \% \text { with } \geq 12 \% \\
\text { or } 200 \mathrm{ml} \text { increase after BDR }\end{array}$ & $\begin{array}{l}\text { SEVERE - hospitalization/ER therapy; } \\
\text { need for systemic steroids for } 3 \text { days; } \\
>30 \% \text { decrease inPEFm for } 2 \text { days }\end{array}$ \\
\hline $\begin{array}{l}\text { Bousquet } \\
(2007)[21]\end{array}$ & $\begin{array}{l}>12 \text { yrs with persistent asthma; ICS } 800-1600 \mu \mathrm{g} / \mathrm{d} \\
\text { or ICS-LABA } 400-1000 \mu \mathrm{g} / \mathrm{d} ; \mathrm{FEV}_{1}>50 \% \text { or }>12 \% \text { BDR; } \\
\geq 1 \text { exacerbation in the last year }\end{array}$ & $\begin{array}{l}\text { SEVERE - hospitalization/ER therapy; } \\
\text { need for systemic steroids for } 3 \text { days }\end{array}$ \\
\hline $\begin{array}{l}\text { Kuna } \\
\text { (2007) [22] }\end{array}$ & $\begin{array}{l}>12 \text { yrs with asthma (ATS) for } 6 \text { months; ICS }>3 \text { months; } \\
\geq 500 \mu \mathrm{g} / \mathrm{d} \text { or }>1000 \mu \mathrm{g} / \mathrm{d} \text { other; } \mathrm{FEV}_{1}>50 \% \text { with } 12 \% \text { BDR; } \\
\geq 1 \text { exacerbation in } 1 \text { year }\end{array}$ & $\begin{array}{l}\text { SEVERE - hospitalization/ER therapy; } \\
\text { need for systemic steroids for } 3 \text { days }\end{array}$ \\
\hline $\begin{array}{l}\text { Sears } \\
(2008)[23]\end{array}$ & $\begin{array}{l}>12 \text { yrs with asthma (ATS) for }>3 \text { months; }>400 \mu \mathrm{g} / \mathrm{d} \\
\text { ICS use; } \geq 3 \text { inhalation of reliever medicine } 7 \text { days prior }\end{array}$ & $\begin{array}{l}\text { SEVERE - hospitalization/ER therapy; } \\
\text { need for systemic steroids for } 3 \text { days }\end{array}$ \\
\hline
\end{tabular}

cline in the number of exacerbations as many patients had more than one exacerbation (total severe exacerbations 640 in the ICS trials $[16,20]$ versus 374 in the SMART group; and, 1304 in the ICSLABA trials [19, 21-23] versus 525 in the SMART group). Several other reviews have also suggested benefits of the SMART approach but only a single study used the systematic review methodology [810] In the only meta-analysis by Cates et al, the authors included only four studies unlike the eight studies included in the current study [10]. More- over, they also included unpublished data, and inclusion of unpublished data in meta-analyses remains controversial due to the lack of quality control and associated peer review of these data [24].

One major concern with the SMART approach was the fear of using excessive doses of ICS when compared to traditional approaches. However, when the mean doses of ICS are summated from the different trials, the dose of ICS used in the SMART approach was similar or even lesser when compared to the traditional approaches (sum of the

Table 4. - Quality of individual studies assessed by the Jadad score

\begin{tabular}{lccccc}
\hline Author & Randomization & Blinding & $\begin{array}{c}\text { Withdrawals } \\
\text { / Dropouts }\end{array}$ & $\begin{array}{c}\text { Method of Blinding } \\
\text { Described }\end{array}$ & $\begin{array}{c}\text { Randomization } \\
\text { Method }\end{array}$ \\
\hline Scicchitano et al [16] & 1 & 1 & 0 & 1 & 1 \\
O'Byrne et al [17] & 1 & 1 & 0 & 0 & 1 \\
Vogelmeier et al [18] & 1 & 0 & 0 & 0 & 1 \\
Rabe et al [19] & 1 & 1 & - & 0 & 1 \\
Rabe et al [20] & 1 & 1 & 0 & 1 & 0 \\
Bousquet et al [21] & 1 & 1 & 1 & 0 & 1 \\
Kuna et al [22] & 1 & 1 & 1 & 1 & 1 \\
Sears et al [23] & 1 & 0 & 1 & 0 & 0 \\
\hline
\end{tabular}


Table 5. - Compliance with study medications reported in various studies

\begin{tabular}{|c|c|}
\hline Author (Year) & Compliance with study medication \\
\hline $\begin{array}{l}\text { Scicchitano } \\
(2004)[16]\end{array}$ & Self reported adherence to study medications was $99 \%$ and similar for both treatment groups \\
\hline $\begin{array}{l}\text { O’Byrne } \\
(2005)[17]\end{array}$ & $\begin{array}{l}\text { Self reported compliance was similar for both treatment groups (compliance } 84-85 \% \text { of days per year; } \\
\text { non-compliance reported on } 3 \% \text { of days per year; incomplete records on } 12-13 \% \text { days per year }\end{array}$ \\
\hline $\begin{array}{l}\text { Vogelmeier } \\
(2005)[18]\end{array}$ & Not available \\
\hline $\begin{array}{l}\text { Rabe } \\
(2006)[19]\end{array}$ & Both groups high levels of adherence, mean $>97 \%$ in both the groups \\
\hline $\begin{array}{l}\text { Rabe } \\
(2006)[20]\end{array}$ & Self reported adherence to treatment was equally high in all groups ( $99 \%$ of patients) \\
\hline $\begin{array}{l}\text { Bousquet } \\
\text { (2007) [21] }\end{array}$ & $\begin{array}{l}\text { Self reported adherence to treatment was high (mean use } 98 \% \text { according to patient diary cards) } \\
\text { in both the groups }\end{array}$ \\
\hline $\begin{array}{l}\text { Kuna } \\
(2007)[22]\end{array}$ & $\begin{array}{l}\text { Self reported adherence to treatment was high ( } 99 \% \text { of patients in all groups reported taking } 81 \% \\
\text { of their maintenance medications) }\end{array}$ \\
\hline $\begin{array}{l}\text { Sears } \\
(2008)[23]\end{array}$ & Not available \\
\hline
\end{tabular}

mean beclamethasone dipropionate equivalent ICS dose used was 2498 micrograms in the ICS trials $[16,17,20]$ versus 1217 micrograms in the SMART group; and, 5931 micrograms in the ICSLABA trials [17-19, 21-23] versus 4890 in the SMART group). Thus exacerbations could be sig- nificantly reduced with the SMART approach with equivalent or even lesser dosages of ICS.

There are significant benefits of preventing severe exacerbations. First and foremost, the prevention of exacerbations indicates optimal asthma control which is the primary goal of therapy [2].

\begin{tabular}{|c|c|c|c|c|c|c|c|c|c|c|}
\hline Study or Subgroup & $\begin{array}{l}\text { SMAR } \\
\text { Events }\end{array}$ & RT & $\begin{array}{l}\text { ICS-LA } \\
\text { Events }\end{array}$ & $\begin{array}{l}\text { BA } \\
\text { Total } \\
\end{array}$ & Weight & $\begin{array}{l}\text { Odds Ratio } \\
\text { M-H, Random, } 95 \% \mathrm{CI}\end{array}$ & \multicolumn{4}{|c|}{$\begin{array}{l}\text { Odds Ratio } \\
\text { M-H, Random, } 95 \% \mathrm{Cl}\end{array}$} \\
\hline \multicolumn{11}{|c|}{ 1.1.1 Severe exacerbations } \\
\hline O'Byrne (2005) & 148 & 925 & 245 & 909 & $17.8 \%$ & $0.52[0.41,0.65]$ & & & & \\
\hline Vogelmeier (2005) & 159 & 1067 & 204 & 1076 & $17.9 \%$ & $0.75[0.60,0.94]$ & & & & \\
\hline Rabe (2006) & 143 & 1107 & 440 & 2275 & $19.1 \%$ & $0.62[0.50,0.76]$ & & & & \\
\hline Bousquet (2007) & 108 & 1151 & 130 & 1153 & $15.9 \%$ & $0.81[0.62,1.07]$ & & & & \\
\hline Kuna (2007) & 94 & 1107 & 381 & 2228 & $17.4 \%$ & $0.45[0.35,0.57]$ & & & & \\
\hline $\begin{array}{l}\text { Sears }(2008) \\
\text { Subtotal }(95 \% \mathrm{Cl})\end{array}$ & 61 & $\begin{array}{r}772 \\
6129\end{array}$ & 63 & $\begin{array}{r}766 \\
8407\end{array}$ & $\begin{array}{r}11.9 \% \\
100.0 \%\end{array}$ & $\begin{array}{l}0.96[0.66,1.38] \\
\mathbf{0 . 6 5}[0.53,0.80]\end{array}$ & & & & \\
\hline \multicolumn{11}{|c|}{$\begin{array}{l}\text { Heterogeneity: } \mathrm{Tau}^{2}=0.05 ; \mathrm{Chi}^{2}=21.34, \mathrm{df}=5(\mathrm{P}=0.0007) ; \mathrm{I}^{2}=77 \% \\
\text { Test for overall effect: } Z=4.04(P<0.0001)\end{array}$} \\
\hline \multicolumn{11}{|c|}{ 1.1.3 Severe exacerbations requiring ER/hospitalization } \\
\hline Vogelmeier (2005) & 31 & 1067 & 46 & 1076 & $17.4 \%$ & $0.67[0.42,1.07]$ & & & & \\
\hline Rabe (2006) & 54 & 1107 & 166 & 2275 & $26.9 \%$ & $0.65[0.48,0.89]$ & & & & \\
\hline Kuna (2007) & 48 & 1107 & 120 & 2228 & $24.8 \%$ & $0.80[0.57,1.12]$ & & & & \\
\hline Bousquet (2007) & 39 & 1151 & 59 & 1153 & $20.1 \%$ & $0.65[0.43,0.98]$ & & & & \\
\hline $\begin{array}{l}\text { Sears }(2008) \\
\text { Subtotal }(95 \% \mathrm{Cl})\end{array}$ & 16 & $\begin{array}{r}772 \\
5204\end{array}$ & 23 & $\begin{array}{r}766 \\
7498\end{array}$ & $\begin{array}{r}10.8 \% \\
100.0 \%\end{array}$ & $\begin{array}{l}0.68[0.36,1.30] \\
0.69[0.58,0.83]\end{array}$ & & & & \\
\hline \multirow{2}{*}{\multicolumn{11}{|c|}{$\begin{array}{l}\text { Total events } \quad 188 \quad 414 \\
\text { Heterogeneity: } \text { Tau }^{2}=0.00 ; \mathrm{Ch}^{2}=0.89, \mathrm{df}=4(\mathrm{P}=0.93) ; \mathrm{I}^{2}=0 \% \\
\text { Test for overall effect: } \mathrm{Z}=4.03(\mathrm{P}<0.0001)\end{array}$}} \\
\hline & & & & & & & & & & \\
\hline & & & & & & & 0.2 & $\begin{array}{cc}0.5 & 1 \\
\text { SMART }\end{array}$ & $\begin{array}{ll}1 & 1 \\
1 & 2 \\
\text { ICS-LABA }\end{array}$ & 5 \\
\hline
\end{tabular}

Fig. 2 - Forest plot showing the occurrence of exacerbations in the SMART approach versus fixed dose ICS-LABA combination. The occurrence of severe exacerbations and severe exacerbations requiring ER/hospitalization was significantly decreased in the SMART approach group (odds ratio with $95 \%$ confidence intervals, random effects model). 


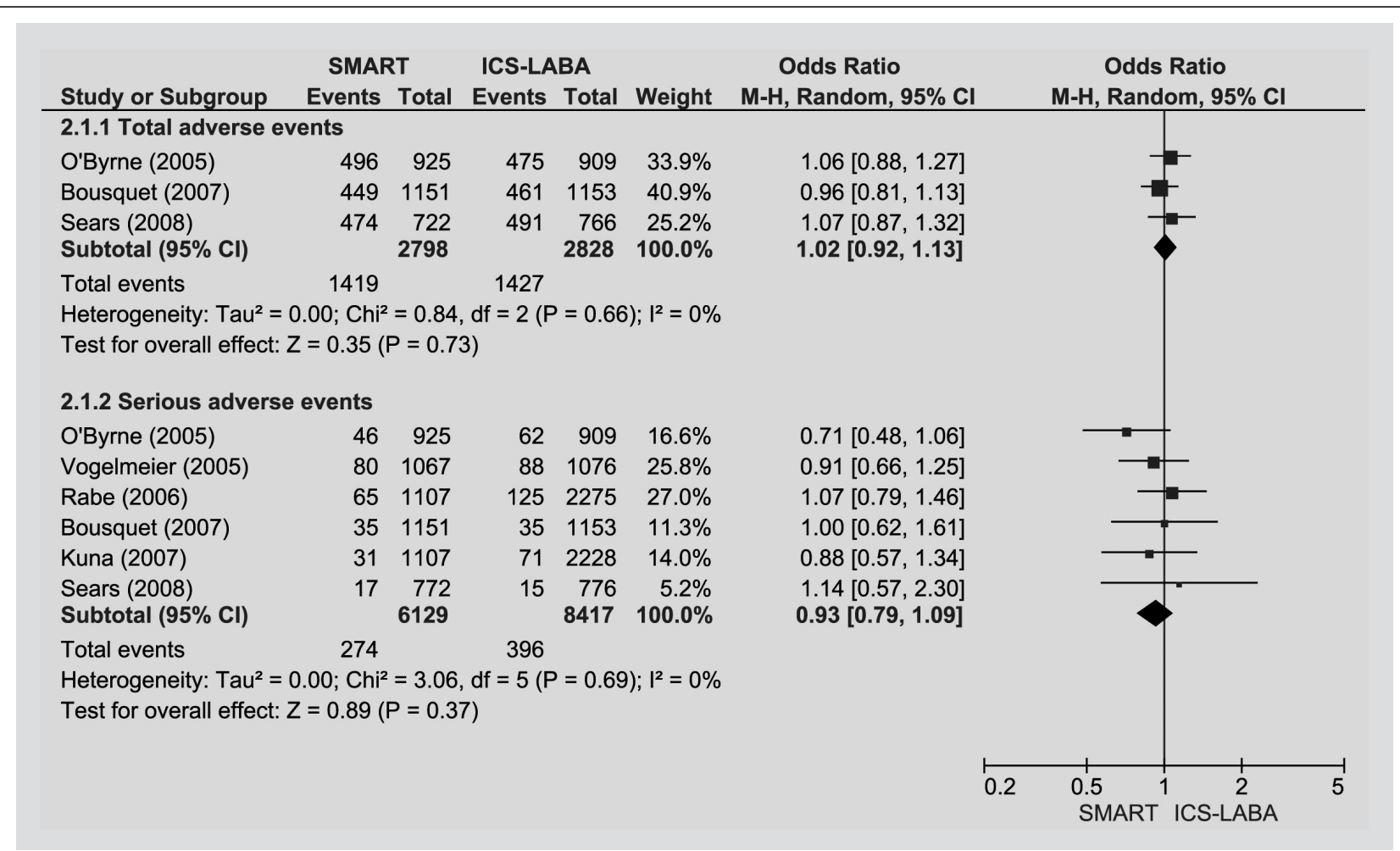

Fig. 3 - Forest plot showing the occurrence of adverse events in the SMART approach versus fixed dose ICS-LABA combination. The occurrence of adverse events was similar in the two groups (odds ratio with $95 \%$ confidence intervals, random effects model).

Recently, it has also been shown that severe exacerbations are associated with excess lung function decline in asthma $[25,26]$. Importantly, treatment with low doses of ICS was associated with reduced risk of a severe exacerbation, and an attenuation of the decline of lung function [26]. Thus the use of SMART approach has the potential to prevent lung function decline in patients with asthma by preventing severe exacerbations. Finally, by preventing severe exacerbations, the SMART approach can decrease the health-care costs of physician visit, emergency room visit and hospitalization.

Asthma therapy has progressed from ICS to ICS-LABA combination single inhalers as they are effective, convenient to use and most importantly ensure that the ICS is not discontinued when the LABA is added. The combination of ICS-LABA is also synergistic in their anti-inflammatory mechanism [27]. In this approach, the use of formoterol has added advantages. Formoterol has a rapid onset

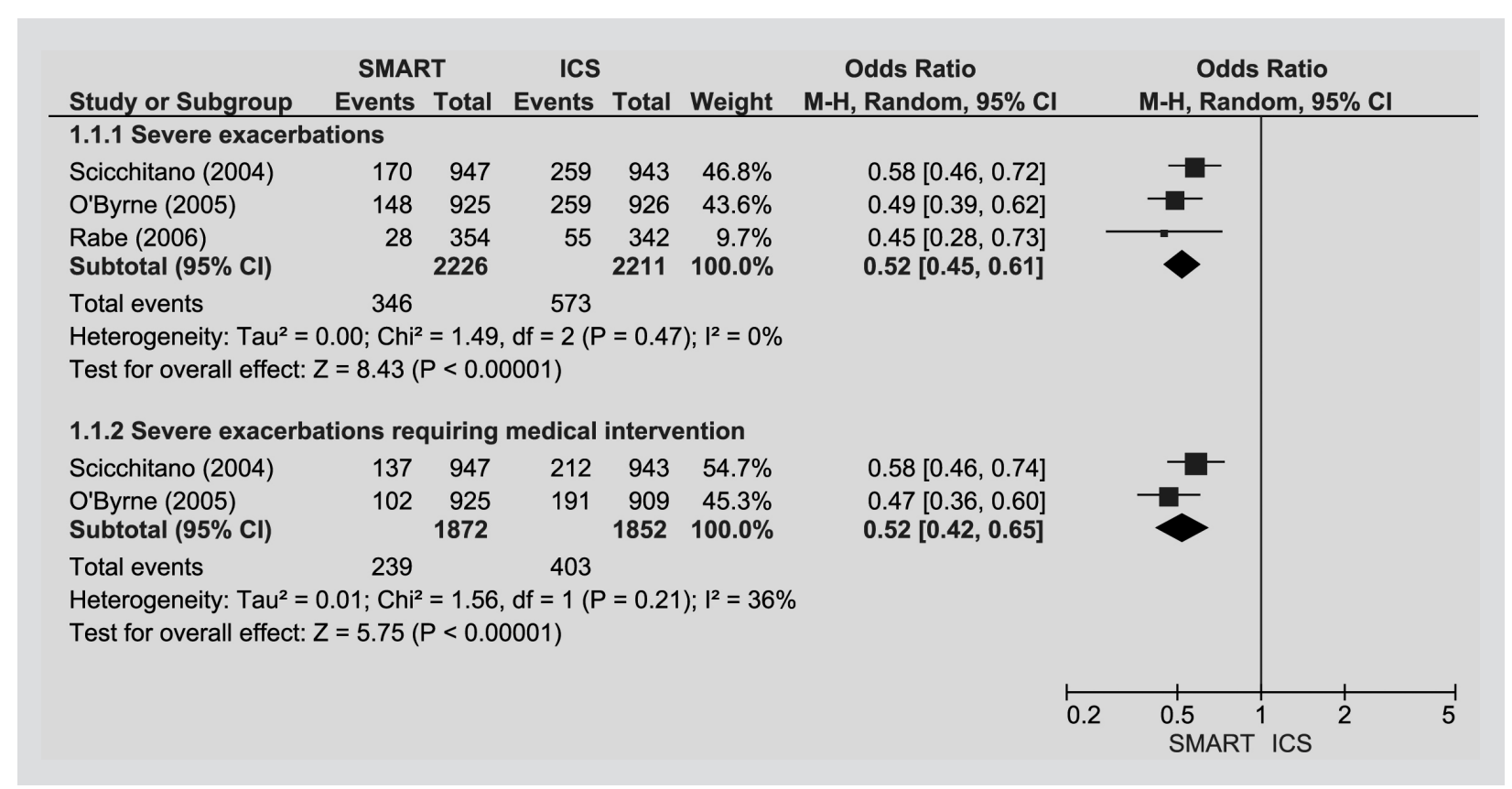

Fig. 4 - Forest plot showing the occurrence of exacerbations in the SMART approach versus fixed dose ICS. The occurrence of severe exacerbations and severe exacerbations requiring medical intervention was significantly decreased in the SMART approach group (odds ratio with $95 \%$ confidence intervals, random effects model). 


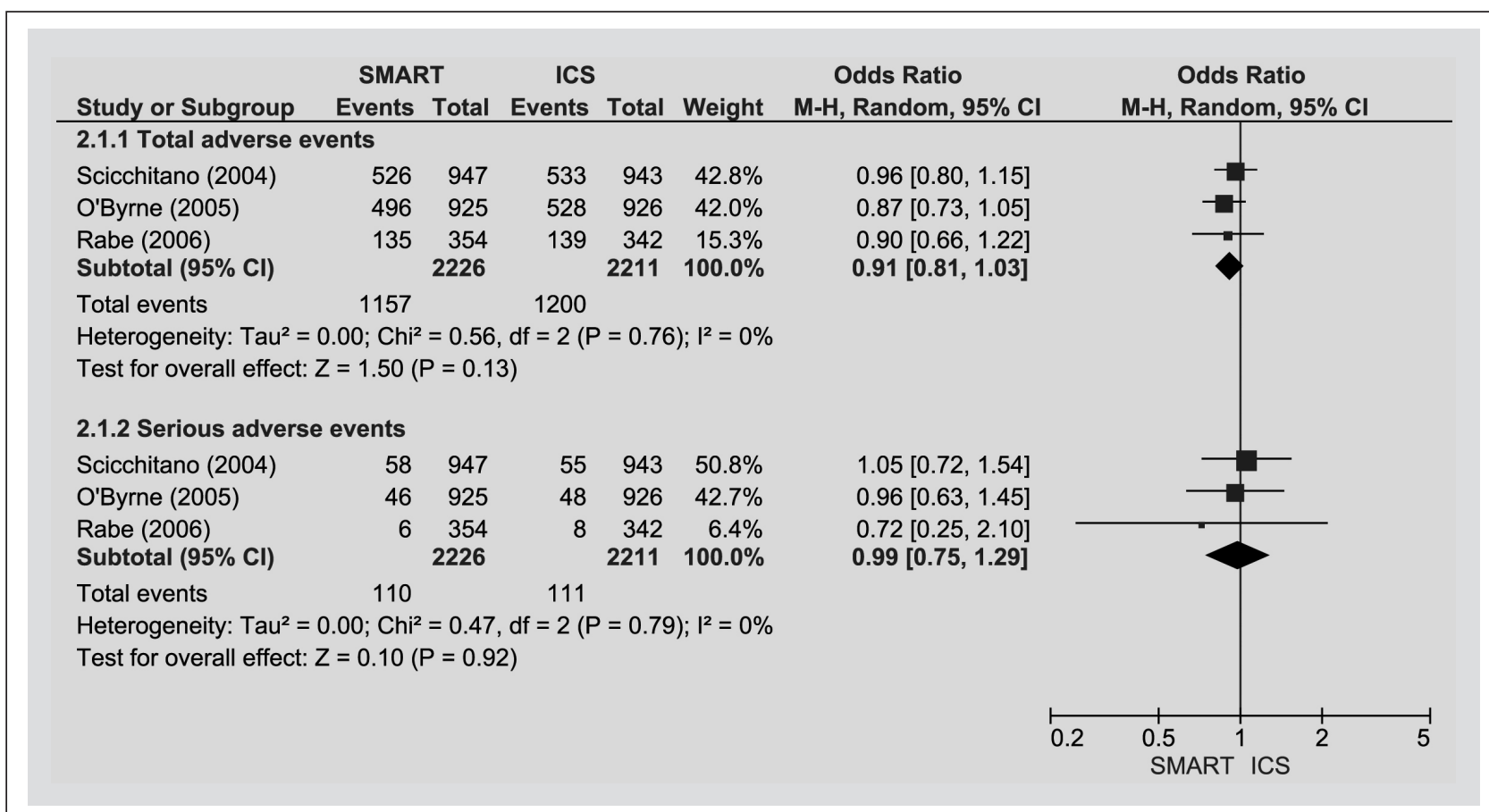

Fig. 5 - Forest plot showing the occurrence of adverse events in the SMART approach versus fixed dose ICS. The occurrence of adverse events was similar in the two groups (odds ratio with $95 \%$ confidence intervals, random effects model).

of action and a long bronchodilator effect [28], has similar efficacy to salbutamol but with a favorable side-effect profile [29], a steeper bronchodilator and bronchoprotective dose response curve than salmeterol [30, 31]. However, despite the use of combination ICS-LABA inhalers and as-needed reliever medications, patients still continue to experience exacerbations [5]. The use of the SMART approach will not only simplify but also increase the efficacy of asthma therapy with a single inhaler use for both maintenance and control.

All the studies using the SMART approach have used the turbuhaler device for drug delivery. Does this mean that the SMART approach should be used only with the turbuhaler device? Probably yes, for now. However, a recent study which evaluated the safety and efficacy profile of a novel hydrofluoroalkane (HFA) pressurized metered-dose inhaler formulation of budesonide-formoterol in comparison to budesonide-formoterol turbuhaler showed no clinically significant differences between treatment groups in the nature, incidence or severity of adverse events or laboratory parameters [32]. Thus, it is probable that it is the SMART approach rather than the device which is more important. The basis for this therapy is the combination of a rapid-acting LABA and ICS. The rapidacting LABA quickly relieves the symptoms whereas the ICS suppresses the inflammation thereby aborting the exacerbation in its earliest stage $[8,9]$. However, further studies are needed to confirm the efficacy of the SMART approach administered via turbuhaler versus other devices and formulations. The current evidence suggests that one should use turbuhaler to replicate the results (benefits) of this study in day-to-day asthma practice.

The limitation of this meta-analysis is the presence of statistical and clinical heterogeneity although we did try to compensate for the statistical heterogeneity by using a random-effects model. The studies included in the meta-analysis have used different doses and devices for asthma control thereby causing a clinically heterogeneous situation. Further, the definitions of severe exacerbations used in different studies have not been uniform. Severe exacerbations were defined by emergency room and/or hospital admission and by the use of oral corticosteroids in some studies but were also defined on the basis of changes in peak expiratory flow in few studies. Ideally, a metaanalysis should only be considered when a group of trials is sufficiently homogeneous in terms of participants, interventions and outcomes. Such a situation is unlikely to occur. In fact, one can argue that, since clinical and methodological diversity always occur in a meta-analysis, statistical heterogeneity is inevitable. The clinical heterogeneity can also be interpreted as beneficial because it suggests that the SMART approach is beneficial in different settings which would reflect its effectiveness in the "real world" situation. As all the studies have been conducted by a single sponsor, the results of this meta-analysis should prompt an individual data (IPD) meta-analysis which would further strengthen the results of this study and will truly replicate the "real world" situation. The IPD meta-analysis would also allow a detailed assessment of short-term control measures such as day time symptoms, nocturnal awakenings and other parameters which was not evaluated in this study.

In conclusion, this meta-analysis demonstrates that formoterol-budesonide in a single inhaler for both maintenance and reliever therapy (without the need for second inhaler for as needed use) is superior in preventing exacerbations when compared to traditional therapy with fixed dose 
ICS or ICS-LABA combination and should probably be adopted as the standard of care for asthma management.

\section{References}

1. Haahtela T, Jarvinen M, Kava T, Kiviranta K, Koskinen $\mathrm{S}$, Lehtonen $\mathrm{K}$, et al. Comparison of a beta 2-agonist, terbutaline, with an inhaled corticosteroid, budesonide, in newly detected asthma. $N$ Engl J Med 1991; 325: 388-92.

2. Global Initiative for Asthma (GINA). Global strategy for asthma management and prevention. Available at http://www.ginasthma.org/Guidelineitem.asp??11=2\&l $2=1 \&$ intId $=60$ [database on the Internet $] 2007$ update [cited 20-08-2008].

3. Pauwels RA, Lofdahl CG, Postma DS, et al. Effect of inhaled formoterol and budesonide on exacerbations of asthma. Formoterol and Corticosteroids Establishing Therapy (FACET) International Study Group. $N$ Engl $J$ Med 1997; 337: 1405-11.

4. O'Byrne PM, Barnes PJ, Rodriguez-Roisin R, et al. Low dose inhaled budesonide and formoterol in mild persistent asthma: the OPTIMA randomized trial. Am J Respir Crit Care Med 2001;164 (8 Pt 1): 1392-7.

5. Bateman ED, Boushey HA, Bousquet J, et al. Can guideline-defined asthma control be achieved? The Gaining Optimal Asthma ControL study. Am J Respir Crit Care Med 2004; 170: 836-44.

6. Tattersfield AE, Postma DS, Barnes PJ, et al. Exacerbations of asthma: a descriptive study of 425 severe exacerbations. The FACET International Study Group. Am J Respir Crit Care Med 1999; 160: 594-9.

7. Partridge MR, van der Molen T, Myrseth SE, Busse WW. Attitudes and actions of asthma patients on regular maintenance therapy: the INSPIRE study. $B M C$ Pulm Med 2006; 6: 13.

8. McCormack PL, Lyseng-Williamson KA. Budesonide/formoterol: a review of its use as maintenance and reliever inhalation therapy in asthma. Drugs 2007; 67: 2407-31.

9. Humbert M, Andersson TL, Buhl R. Budesonide/formoterol for maintenance and reliever therapy in the management of moderate to severe asthma. Allergy 2008; 63: 1567-80.

10. Cates CJ, Lasserson TJ. Combination formoterol and budesonide as maintenance and reliever therapy versus inhaled steroid maintenance for chronic asthma in adults and children. Cochrane Database Syst Rev 2009 (2): CD007313.

11. Jadad AR, Moore RA, Carroll D, et al. Assessing the quality of reports of randomized clinical trials: is blinding necessary? Control Clin Trials 1996; 17: 1-12.

12. Kjaergard LL, Villumsen J, Gluud C. Reported methodologic quality and discrepancies between large and small randomized trials in meta-analyses. Ann Intern Med 2001; 135: 982-9.

13. DerSimonian R, Laird N. Meta-analysis in clinical trials. Control Clin Trials 1986; 7: 177-88.

14. Armitage P, Berry G, Matthews JNS. Analysing means and proportions. Statistical methods in medical research. 4th ed. Oxford: Blackwell Science; 2002. p. 83-146.

15. Fleiss JL. Analysis of data from multiclinic trials. Control Clin Trials 1986; 7: 267-75.
16. Scicchitano R, Aalbers R, Ukena D, et al. Efficacy and safety of budesonide/formoterol single inhaler therapy versus a higher dose of budesonide in moderate to severe asthma. Curr Med Res Opin 2004; 20: 1403-18.

17. O'Byrne PM, Bisgaard H, Godard PP, et al. Budesonide/formoterol combination therapy as both maintenance and reliever medication in asthma. Am J Respir Crit Care Med 2005; 171: 129-36.

18. Vogelmeier C, D'Urzo A, Pauwels R, et al. Budesonide/formoterol maintenance and reliever therapy: an effective asthma treatment option? Eur Respir J 2005; 26: 819-28.

19. Rabe KF, Atienza T, Magyar P, Larsson P, Jorup C, Lalloo UG. Effect of budesonide in combination with formoterol for reliever therapy in asthma exacerbations: a randomised controlled, double-blind study. Lancet 2006; 368 (9537): 744-53.

20. Rabe KF, Pizzichini E, Stallberg B, et al. Budesonide/formoterol in a single inhaler for maintenance and relief in mild-to-moderate asthma: a randomized, double-blind trial. Chest 2006; 129: 246-56.

21. Bousquet J, Boulet LP, Peters MJ, et al. Budesonide/ formoterol for maintenance and relief in uncontrolled asthma vs. high-dose salmeterol/fluticasone. Respir Med 2007; 101: 2437-46.

22. Kuna P, Peters MJ, Manjra AI, et al. Effect of budesonide/formoterol maintenance and reliever therapy on asthma exacerbations. Int J Clin Pract 2007; 61: 725-36.

23. Sears MR, Boulet LP, Laviolette M, et al. Budesonide/formoterol maintenance and reliever therapy: impact on airway inflammation in asthma. Eur Respir $J$ 2008; 31: 982-9.

24. Cook DJ, Guyatt GH, Ryan G, et al. Should unpublished data be included in meta-analyses? Current convictions and controversies. JAMA 1993; 269: 2749-53.

25. Bai TR, Vonk JM, Postma DS, Boezen HM. Severe exacerbations predict excess lung function decline in asthma. Eur Respir J 2007; 30: 452-6.

26. O'Byrne PM, Pedersen S, Lamm CJ, Tan WC, Busse WW. Severe exacerbations and decline in lung function in asthma. Am J Respir Crit Care Med 2009; 179: 19-24.

27. Barnes PJ. Scientific rationale for inhaled combination therapy with long-acting beta2-agonists and corticosteroids. Eur Respir J 2002; 19: 182-91.

28. Pauwels RA, Sears MR, Campbell M, et al. Formoterol as relief medication in asthma: a worldwide safety and effectiveness trial. Eur Respir J 2003; 22: 787-94.

29. Najafizadeh K, Sohrab Pour H, Ghadyanee M, Shiehmorteza M, Jamali M, Majdzadeh S. A randomised, double-blind, placebo-controlled study to evaluate the role of formoterol in the management of acute asthma. Emerg Med J 2007; 24: 317-21.

30. Palmqvist M, Ibsen T, Mellen A, Lotvall J. Comparison of the relative efficacy of formoterol and salmeterol in asthmatic patients. Am J Respir Crit Care Med 1999; 160: 244-9.

31. Barnes PJ. Scientific rationale for using a single inhaler for asthma control. Eur Respir J 2007; 29: 587-95.

32. Morice AH, Hochmuth L, Ekelund J, Thoren A, Puterman AS. Comparable long-term safety and efficacy of a novel budesonide/formoterol pressurized metereddose inhaler versus budesonide/formoterol Turbuhaler in adolescents and adults with asthma. Pulm Pharmacol Ther 2008; 21: 32-9. 